\title{
SISTEM IDENTIFIKASI DENGAN QUICK RESPONSE CODE UNTUK PEMBELAJARAN E-LEARNING TERINTEGRASI KE WEB
}

\author{
Muhammad Ilyas Ahibma ${ }^{1}$, Raihan Fauzan ${ }^{2}$ \\ ${ }^{1,2,3}$ Teknik Elektro,Program Studi Elektronika Industri, Politeknik Negeri Jakarta, Jl. \\ Prof.Dr.G.A.Siwabessy, Kampus UI, Depok, 16425 \\ Email : ${ }^{1}$ Milyasahibma@gmail.com, ${ }^{2}$ Rfauzann98@gmail.com
}

\begin{abstract}
At present, Labkom users have not used a security system to access PC usage. The use of safety by using a user's PC in Labkom is essential, especially for participants who are practice scheduled. Therefore, it was made with practice course participants using the QR Code. The design of tools/security systems uses hardware (hardware) and software (software). The hardware consists of a Webcam, a Raspberry Pi TFT Screen, as a microcontroller, a router as a distributor of IP addresses. Webcams approve and approve data on QR Code patterns of practical lecture participants. Identification is made when participants register (log in). Data Results are then transferred to the database. Practical lecture participants have access to use a PC provided by E-Learning in the Labkom after the QR Code data pattern is verified with data in the database.
\end{abstract}

Keywords: QR Code, Raspberry Pi, Webcam, Router, TFT Screen, and database

\begin{abstract}
ABSTRAK
Saat ini, pengguna Labkom belum menggunakan sistem pengaman untuk akses penggunaan PC. Penggunaan pengaman dengan identifikasi pengguna PC di Labkom penting, khususnya peserta kuliah praktik terjadwal. Oleh karena itu, dibuat alat dengan identifikasi peserta mata kuliah praktik menggunakan QR Code. Perancangan alat/sistem pengaman menggunakan perangkat keras (hardware) dan perangkat lunak (software). Hardware terdiri dari Webcam, Layar TFT Raspberry Pi, sebagai mikrokontroler, router sebagai pendistribusi IP Adress. Webcam mengidentifikasi dan memverifikasi data pada pola QR Code peserta kuliah praktis. Identifikasi dilakukan saat peserta melakukan pendaftaran (login). Hasil Data kemudian disimpan pada database. Peserta kuliah praktis memiliki akses untuk menggunakan PC serta mengakses E-Learning di Labkom setelah Data pola QR Code terverifikasi dengan data pada database.
\end{abstract}

Kata Kunci: QR Code, Raspberry Pi, Webcam, Router, Layar TFT, dan database

\section{PENDAHULUAN}

Sistem pembelajaran tanpa batas jarak masih menjadi polemik di beberapa Perguruan Tinggi (PT). Sekelompok Dosen menyikapi positif terkait penggunaan e- learning, walaupun sebagian juga belum/tidak menerimanya. Saat ini sebagain besar mata kuliah di Politeknik Negeri Jakarta (PNJ), khususnya Jurusan Teknik Elektro (JTE), Program Studi (Prodi) Elektronika Industri masih diwajibkan belajar dengan 
tatap muka. Sementara itu tantangan mewujudkan Visi PNJ perlu disikapi target dan sasarannya.Visi PNJ "Menjadi Politeknik Unggul Bertaraf Intrnasional untuk Mendukung Daya Saing Bangsa". E-learning salah satu media menjangkau taraf international. Pengembangannya dan materinya dibuat dalam Bahasa Inggris, peluang terbuka dibaca oleh mahasiswamahasiswa di benua lain, Perbedaan sikap/pandangan ini menjadi inspirasi bagi mahasiswa, pentingnya merintis peluang internasional dengan metode elearning. Manfaat e-learning, solusi untuk Dosen yang berhalangan hadir. Pelaksanaannya memerlukan regulasi untuk mendukung terealisasinya visi PNJ.

Kecenderungan untuk mengembangkan elearning sebagai salah satu alternatif pembelajaran di berbagai lembaga pendidikan dan pelatihan semakin meningkat sejalan dengan perkembangan di bidang teknologi komunikasi dan informasi [1]. Quick Response (QR) Code bertujuan untuk menyampaikan informasi dan mendapatkan respons dengan cepat [2]. Fungsi webcam yaitu memudahkan mengolah pesan secara cepat seperti bertatap muka melalui video secara real time [3]. output HMI untuk meningkatkan interaksi antara mesin dan operator melalui tampilan layar dan memenuhi kebutuhan pengguna terhadap informasi sistem [4].

Usulan untuk merancang bangun system identifikasi pengguna PC di Laboratorium Komputer. QR code scanner diimplementasikan sebagai pengidentifikasi pengguna PC di Laboratorium Komputer (Labkom) JTE. Sistem identifikasi terintegrasi ke web. Akses penggunaan PC menginformasi data mahasiswa yang hadir di kelas. Validasi kehadiran mahasiswa mengikuti pembelajaran e-learning melalui web. Jika QR code teridentifikasi sebagai peserta matakuliah kelas praktik, maka Mahasiswa dapat menggunakan PC. Media webcam jadi sarana pembelajaran tatap muka jarak jauh. Hal ini sangat membantu Dosen yang berhalangan hadir dan mahasiswa tidak dirugikan. Alat TA, terdiri dari QR code scanner dan webcam sebagai input. Mikrokonroler sebagai switch dan pengiriman data lewat web e-learning untuk beberapa fungsi. Dosen yang berhaangan hadir dapat menidentifikasi mahasiswa yang mengikuti kelasnya tersebut. Proses pembelajaran jarak jauh berlangsung real time walau Dosen tidak berada di kelas.

\section{METODE PENELITIAN}

\subsection{Ddiagram blok}

Realisasi keseluruhan sistem sesuai dengan diagram blok sistem (Gambar 1) dan mengacu pada flowchart program Arduino (Gambar 2).

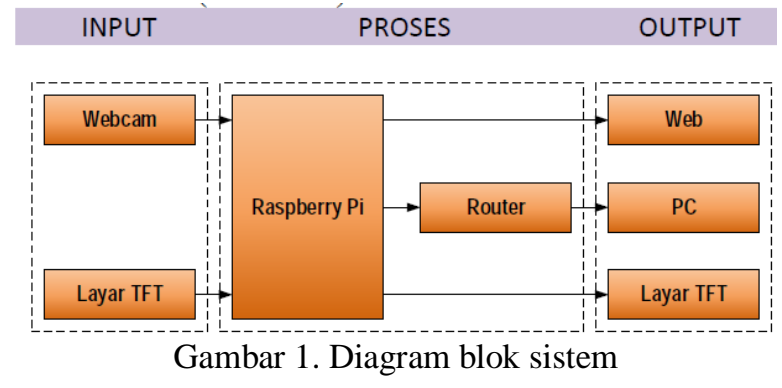

Keterangan Gambar 1

\begin{tabular}{|c|c|c|}
\hline Webcam & : & $\begin{array}{l}\text { Webcam mengidentifikasi } \mathrm{QR} \\
\text { code mahasiswa peserta mata } \\
\text { kuliah praktik }\end{array}$ \\
\hline Mikrokomputer & : & $\begin{array}{l}\text { Raspberry Pi yang terhubung } \\
\text { dengan webcam mendeteksi } \\
\text { pixel pada QR code yang di } \\
\text { terjemahkan menjadi } \\
\text { identitas. Identitas yang telah } \\
\text { diterjemahkan sekaligus } \\
\text { untuk login pada } \\
\text { E-Learning }\end{array}$ \\
\hline $\begin{array}{l}\text { Layar TFT } \\
\text { (HMI) }\end{array}$ & & $\begin{array}{l}\text { Menampilkan informasi PC } \\
\text { LabKom yang masih tersedia }\end{array}$ \\
\hline Router & & $\begin{array}{l}\text { Sebagai penerima informasi } \\
\text { dari raspberry pi } \\
\text { Untuk mengaktifkan PC } \\
\text { LabKom melalui kabel LAN }\end{array}$ \\
\hline Website & & $\begin{array}{l}\text { Website menampilkan } \\
\text { identitas mahasiswa peserta } \\
\text { mata kuliah yang mengakses. } \\
\text { Mahasiswa dapat mengakses } \\
\text { materi mata kuliah }\end{array}$ \\
\hline
\end{tabular}

\subsection{Rancangan Alat}

Perencanaan sistem QR Code pada tugas akhir ini secara umum dibagi menjadi dua bagian yaitu perancangan alat dan pemrograman. Perancangan alat merupakan perancangan seperti pemasangan dan penempatan posisi Webcam, Raspberry Pi serta pembuatan cover alat. Sedangkan perancangan pemrograman adalah pembuatan algoritma sistem pada perangkat lunak yang terkait dengan alur proses, seperti melakukan identifikasi QR Code dan tampilan HMI terkoneksi pada switch PC LabKom. 

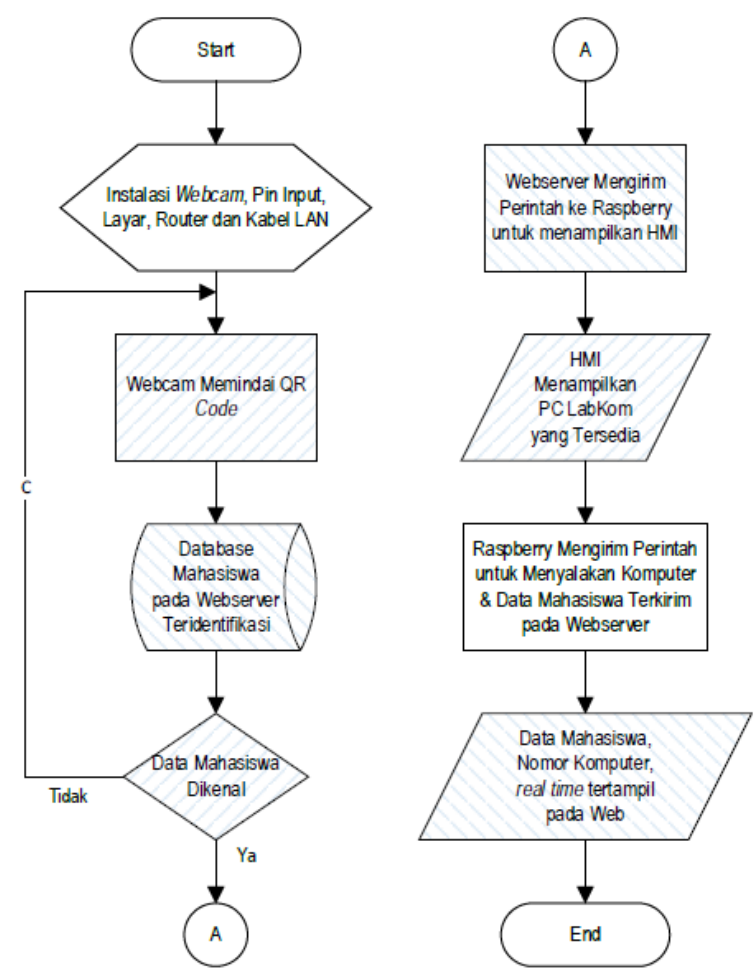

Gambar 2. Flowchart program Arduino

\subsection{Perancangan Database}

Dalam database terdapat tabel Login yang akan menyesuaikan id, nama dan kelas ke tabel Soal. Konektifitas tersebut terjadi apabila Mahasiswa yang mengakses, Sedangkan jika Dosen yang mengakses langsung terhubung pada tabel Stat. Akses Mahasiswa dari tabel login menyesuaikan kelas jam mulai dan kelas jam akhir yg terdapat pada tabel Soal.

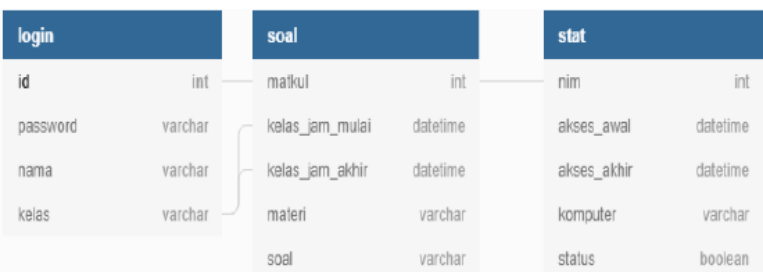

Gambar 3. Tabel skema database

2.4 Proses Pengiriman Identitas Mahasiswa ke Webserver

Pengiriman identitas mahasiswa dikirim setelah mahasiswa memilih PC LabKom pada layar TFT. Identitas mahasiswa akan disamakan dengan Database pada Webserver. Setelah itu mahasiswa dapat mengakses materi mata kuliah.

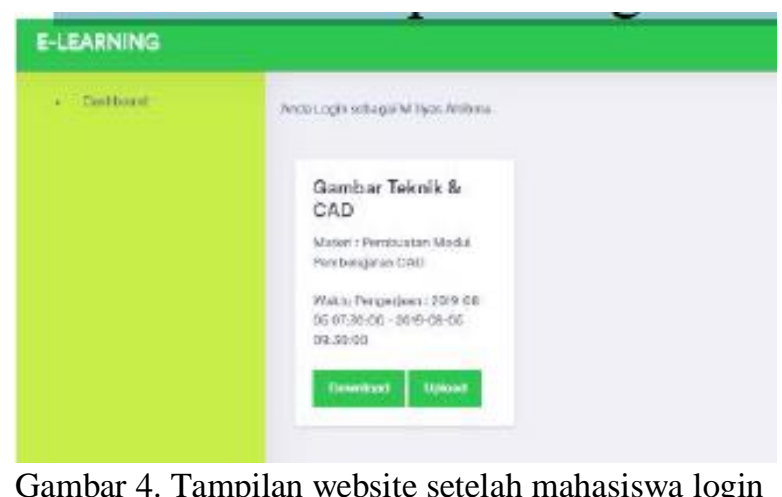

Gambar 4. Tampilan website setelah mahasiswa login

2.4 Wiring diagram alat

Wiring diagram alat dapat dilihat pada Gambar 5 dan 6.

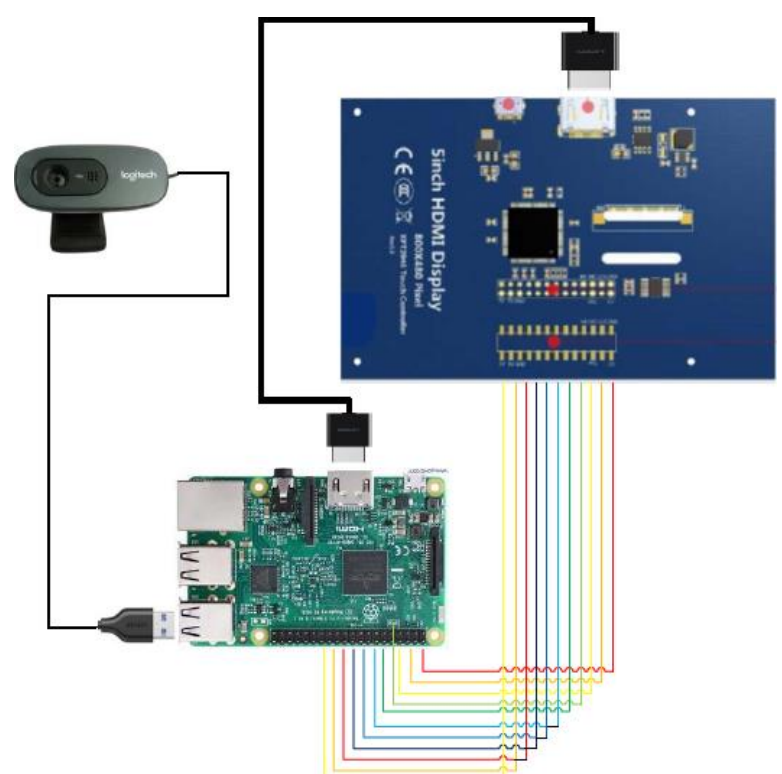

Gambar 5. Koneksi Raspberry Pi dengan Webcam dan Layar TFT

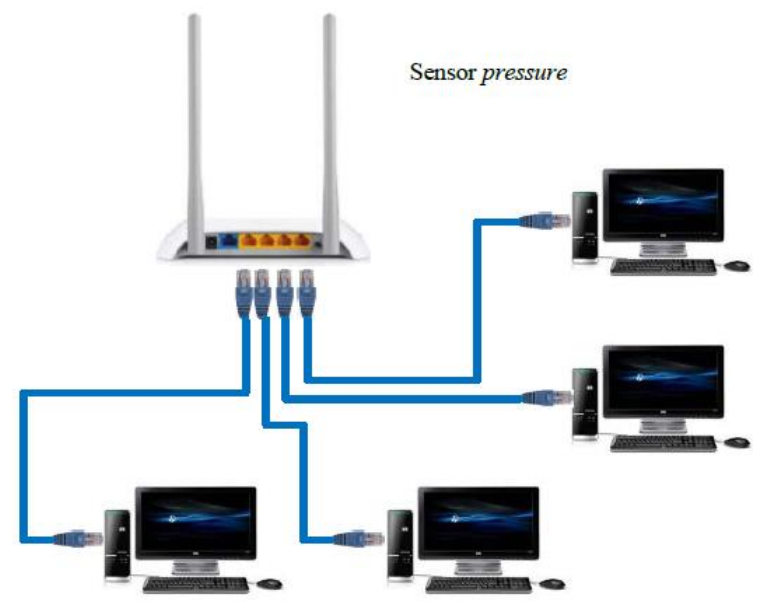

Gambar 6 Koneksi Router dengan PC LabKom 


\section{Sistem indentifikasi dengan quick response code untuk pembelajaran}

\section{HASIL dan PEMBAHASAN}

3.1 Data hasil pengujian jarak pindai webcam terhadap QR code

Jarak pindai webcam terhadap QR code sangat berpengaruh seperti terlihat pada Tabel 1. Tampilan QR code pada layer TFT dapat dilihat pada Gambar 7.

Tabel 1 Hasil jarak pindai

\begin{tabular}{cc}
\hline Jarak $(\mathrm{cm})$ & Hasil \\
\hline 5 & Gagal \\
10 & Berhasil \\
15 & Berhasil \\
20 & Berhasil \\
25 & Berhasil \\
30 & Berhasil \\
35 & Berhasil \\
40 & Gagal \\
45 & Gagal \\
\hline
\end{tabular}

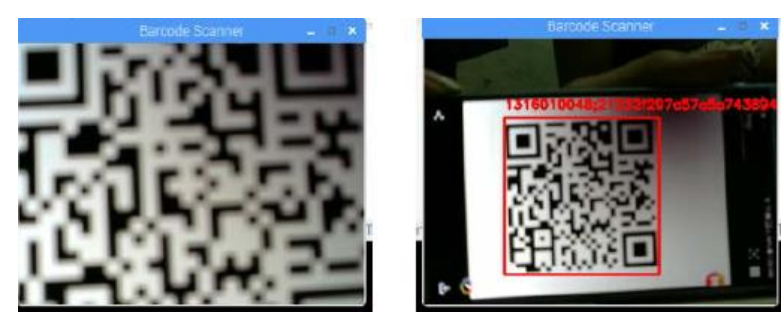

Gambar 7. Tampilan QR Code pada layer TFT

Dari Tabel 1 terlihat bahwa QR code yang terpindai pada jarak $10 \mathrm{~cm}$ sampai dengan $35 \mathrm{~cm}$. Sedangkan pada posisi $5 \mathrm{~cm}, 40 \mathrm{~cm}$, dan $45 \mathrm{~cm}$ QR code tidak terpindai oleh webcam.

\subsection{Data hasil pengujian akses e-learning dengan QR code}

E-learning dapat diakses oleh mahasiswa sesuai waktu jam pelajaran dimulai. Mahasiswa dapat login namun tidak bisa mengakses upload dan download materi dan soal. Tombol upload dan download akan berwarna merah seperti terlihat pada Gambar 8.

Jika sudah masuk waktu jam pelajaran, maka tombol upload dan download akan berubah menjadi warna hijau seperti terlihat pada Gambar 9. Dengan perubahan ini, maka mahasiswa dapat mengases materi dan soal serta mengirimkan jawaban soal.

Sedangkan bagi dosen, tampilan akan terlihat seperti pada gambar 10. Dosen dapat melihat siapa saja mahasiswa yang telah mengunduh materi dan mengirimkan soal. Dalam tampilan website dosen tercantum NIM, waktu akses awal, waktu akses akhir, dan status kirim data. Sedangkan pada kolom Komputer tertampil pada nomer berapa Mahasiswa Menggunakan PC. Namun, jika tampilan tersebut 0 berarti Mahasiswa belum melakukan Scan QR Code.

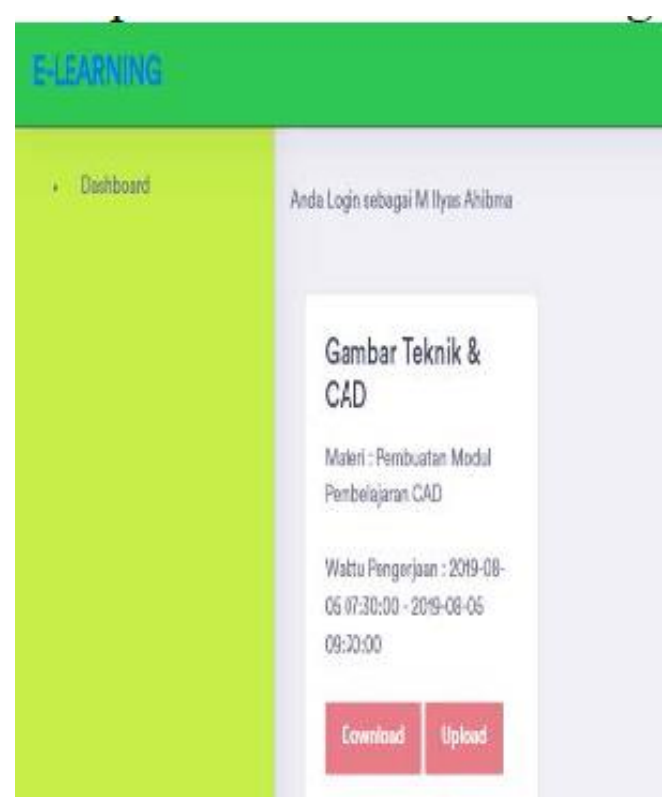

Gambar 8 Tampilan akses e-learning sebelum jam pelajaran mulai

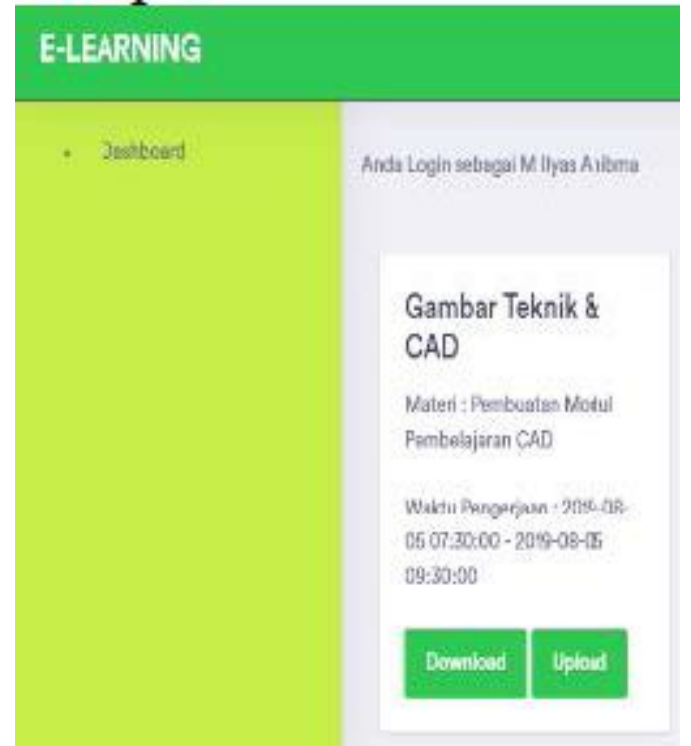

Gambar 9 Tampilan akses $e$-learning setelah jam pelajaran mulai

\begin{tabular}{|c|c|c|c|c|}
\hline NMM & Waku Akcos Aval & Waktu Aksos Akhif & Komputor & Status Pengoriata \\
\hline 136010048 & 2019-08-12 15:206:44 & \begin{tabular}{|l|} 
2019-08-12 16:04:01 \\
\end{tabular} & 1 & Belum Upload \\
\hline 1316010087 & $2019-08-12$ 16:C4:32 & \begin{tabular}{|l|}
$\mid 2019-08-1216: 56: 53$ \\
\end{tabular} & 1 & Belum Upload \\
\hline 1316010068 & 2019-08-13 01:36:46 & |2019-08-13 02:07:31 & 1 & Belum Upload \\
\hline 136010060 & |0000-00-00 00:00:00 & |0000-00-0000:00:00 & 0 & Belum Upload \\
\hline 1316010016 & 2019-08-12 10:68:10 & 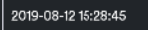 & 1 & Belum Upload \\
\hline 1316010015 & 0000-00-00 00:00:00 & 0000-00-0000:00:00 & 0 & Belum Upload \\
\hline 1316010042 & 2019-08-12 7:C:15 & $0000-00-0000: 00: 00$ & 3 & Belum Upload \\
\hline 136010083 & 2019-08-12 04:51:12 & 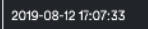 & 4 & Belum Upload \\
\hline 136010026 & 2019-08-12 04:53:24 & \begin{tabular}{|l|}
$\mid 2019-08-12 ~ 04: 53: 27$ \\
\end{tabular} & 3 & Belum Upload \\
\hline $13: 6010033$ & $0000-00-0000: 00: 00$ & | $0000-00-0000: 00: 00$ & 0 & | Belum Upload \\
\hline
\end{tabular}

Gambar 10 Tampilan akses $e$-learning dosen 


\section{Sistem indentifikasi dengan quick response code untuk pembelajaran}

\section{KESIMPULAN}

Berdasarkan beberapa percobaan yang telah dilakukan, dapat disimpulkan:

a. Hasil Pengujian sensor $Q R$ Code menunjukkan terjadinya perbedaan pengukuran yang disebakan oleh perbedaan jarak penempatan QR Code.

b. Kemampuan jarak pindai webcam terhadap QR Code yaitu $10 \mathrm{~cm}$ hingga $35 \mathrm{~cm}$. Pada jarak $5 \mathrm{~cm}$ dan $40 \mathrm{~cm}$ atau lebih webcam tidak mampu memindai QR code.

c. Seorang mahasiswa hanya dapat mengakses satu PC Labkom dengan menggunakan QR code.

d. Perubahan waktu Login dapat mempengaruhi Tampilan dan Akses yg tertampil

e. Scan atau tidak juga dapat mempengaruhi tabel $E$ Learning Dosen. Hasil uji tersebut membuktikan bahwa Mengakses sesuai jadwal sangat mempengaruhi Akses pada E-Learning.

\section{DAFTAR PUSTAKA}

[1] M. Pasca Nugraha, Dr. Ir. Rinaldi Munir M.TKonferensi Nasional Informatika, KNIF, "Pengembangan Aplikasi QR Code Generator dan QR Code Reader dari Data Berbentuk Image," 2011, ISSN: 2087 - 3328
[2] Qurotul.A, Untung.R, Anggy.F-Jurnal Ilmiah SISFOTENIKA," Penerapan QRCode Sebagai Media Pelayanan Untuk Absensi Pada Website Berbasis PHP Native ," Vol. 8, No. 1, Januari, 2018

[3] Qashlim Akhmad dan Hasruddin. "Implementasi Teknologi QR-Code Untuk Kartu Identitas". Jurnal Ilmu Komputer, vol 1, no. 2, hh. 1-6, ISSN: $2442-4512$.

[4] Sugiantoro Bambang dan Hasan Fuad. "Pengembangan Qr Code Scanner Berbasis Android untuk Sistem Informasi Museum Sonobudoyo Yogyakarta". Telematika, vol. 12, no. 2, hh. 135-145, ISSN: 1829-667X

[5] Dwiyaniti, M., Atmaja, I. T., Firdaus, Y., \& Noveansyah, H. 2019. Pengembangan Multiplatform Pengendali Dan Pemonitor Perangkat Listrik Pada Miniatur Smart Home. ELECTRICES, 1(1), 1-8.

[6] Irawan Bei H, Riady Sasmitoh R dan Sofi, Khalis "Penerapan Absensi Kuliah Berbasis QR Code dengan Modul Raspberry Pi3 Menggunakan Metode Arsitektur Zachman Framework". Prosiding Seminar Nasional Unimus, vol. 1, no. 1, hh. 718-730, ISSN: 2654-3168 